\title{
Políticas Públicas EN SAlud: APROXIMACión A UN ANÁLISIS
}

\author{
GRUPO DE INVESTIGACIÓN EN GESTIÓN Y POLÍTICAS EN SALUD \\ FACULTAD NACIONAL DE SALUD PÚBLICA "HÉCTOR ABAD GÓMEZ", \\ UNIVERSIDAD DE ANTIOQUIA \\ COLOMBIA, 2008
}

Rachelle Balbinot *)

Esta publicação é resultado de um trabalho realizado por um grupo de pesquisadores na Colômbia, especialmente na Faculdade de Saúde Pública e Universidade de Antioquia, para tratar de tema central na questão do direito à saúde: as políticas públicas. As mudanças ocorridas no setor saúde nas últimas décadas foram o mote principal para a organização deste grupo, bem como a eleição dos temas tratados.

Inicialmente é organizado um quadro teórico metodológico sobre as políticas públicas de saúde, que será a linha mestra a ser seguida nos demais capítulos.

Em um segundo momento serão analisadas as políticas públicas propriamente ditas em diversas áreas: atenção à saúde, objetivos do milênio e o setor saúde, primeira infância, lactância, crianças em situação de rua, deslocados internos ${ }^{1}$, insuficiência renal crônica.

No terceiro bloco estão os resultados das entrevistas realizadas com os principais atores das políticas públicas, aqueles a quem cabe decidir ou influenciar nas políticas públicas de saúde na Colômbia.

As políticas públicas são normas com o objetivo de parametrizar os cuidados dispensados à saúde, pelo Poder Público, e, em geral, para o atendimento de grupos específicos ou população com agravos específicos.

O texto tem como norte o seguinte conceito: "as políticas públicas são

(*) Doutora em Integração da América Latina, Universidade de São Paulo (USP). Pesquisadora do Núcleo de Pesquisas em Direito Sanitário da Universidade de São Paulo. Advogada. São Paulo/SP Brasil. E-mail: <rachebalbi@gmail.com>.

Texto recebido em 19.09.11

(1) Desplazados: na Colômbia são indivíduos ou grupos que se deslocam internamente, em razão dos conflitos, sendo esta situação tão (re)conhecida que existem políticas públicas para pessoas que vivem nesta situação. 
processos de construção coletiva de iniciativas, decisões e ações, respaldadas e legitimadas pelo estado, para dar resposta a problemas socialmente reconhecidos, em um contexto econômico, político, social e cultural particular"2.

Uma das questões presentes quando se estuda o direito à saúde é a necessidade de ampliar a abordagem, sendo sempre imperioso considerar a complexidade do conceito em razão da abrangência, situação social, cultural, política, econômica. Para tanto, a construção das políticas públicas necessita de uma série de atores que poderão contribuir para que sejam efetivas e conformadas com uma dada realidade. O grupo de pesquisadores aponta os seguintes "agentes críticos":

a) patrocinadores, formuladores de políticas e responsáveis políticos;

b) diretores de programas, gestores e profissionais;

c) destinatários diretos e indiretos;

d) outros que atuam como referência: profissionais e responsáveis por políticas similares, cientistas sociais e especialistas e

e) instituições internacionais e transnacionais que intervêm no projeto e efetivação das políticas públicas nacionais. ${ }^{3}$

Em razão do conceito, bem como dos atores envolvidos, a política pública não pode ser estudada como um desdobramento linear, ou um modelo único, mas, sim, como ela é elaborada, implementada, avaliada, isto é, nas suas múltiplas acepções, que são definidas em razão do cenário político, econômico e dos atores envolvidos no processo.

É possível verificar a flexibilidade das políticas públicas, pois são, "de certo modo, microplanos ou planos pontuais, que visam à racionalização técnica da ação do Poder Público para a realização de objetivos determinados, com a obtenção de certos resultados". ${ }^{4}$

O fato de serem planos pontuais precisa ser delimitado de tal forma a cumprir adequadamente e em um prazo definido o objetivo pretendido. Para que se tenha sucesso na implementação das políticas públicas é preciso não só um quadro bem detalhado da situação a ser enfrentada, bem como a estruturação de um plano que seja conveniente e eficiente para dada situação, e é aí que entram as situações socioeconômicas e culturais que poderão influenciar no sucesso ou não da empreitada estatal. Ainda por se tratar de formulação que visa atingir certos indivíduos ou grupos é imperioso que eles tomem parte nas decisões, a fim de legitimá-las quando estas forem convertidas em normas oficiais.

(2) Políticas públicas en salud, p. 5.

(3) Políticas públicas en salud, p. 4-5.

(4) BUCCI, Maria Paula Dallari. O Conceito de Política Pública em Direito. In: BUCCI, Maria Paula Dallari (org.) Políticas Públicas: Reflexões sobre o conceito Jurídico. São Paulo: Saraiva, 2006. p. 27. 
Existe um consenso de que a implementação de políticas públicas pode provocar transformações profundas em uma dada comunidade. Para a análise de políticas públicas em saúde são propostas três fases: 1) formulação (é o quadro detalhado de situações que influenciarão a tomada de decisão); 2) implementação (contexto já definido de como se dará a efetivação da política pública de saúde, considerando obstáculos e aspectos facilitadores); 3) avaliação (aspectos relacionados aos meios, resultados, impactos, eficiência e satisfação). Nos capítulos dois a oito estas três fases propostas serão utilizadas para analisar determinadas políticas públicas de saúde na Colômbia.

No primeiro tema tratado é evidenciada uma situação existente no Brasil, o direito à saúde e sua relação com o Poder Judiciário. Na Colômbia, um estudo realizado mostrou o aumento de sentenças na área da saúde: em 1992 eram 5,8\%; em 2003, chegaram a 33,4\% dos casos.. Nesse capítulo a conclusão mostra que ainda não existe garantia do direito à saúde de forma adequada, o que é verificado em razão das decisões da Corte Constitucional, que é o local que garante, em última instância, o direito à saúde.

A discussão sobre como alcançar os Objetivos do Milênio em relação à saúde foi entendida como um importante espaço que mostrou a prevenção e a promoção como estratégias eficientes para a melhora do nível de saúde da população.

Outro capítulo mostra a infância como tema central e coloca a questão dos menores de seis anos como pessoas que necessitam de políticas públicas de saúde especiais para seu desenvolvimento adequado; na Colômbia, em 2005, este grupo representava $12,7 \%$ da população. Outros dados apresentados mostram que a vulnerabilidade dos menores de seis anos deve ser enfrentada de forma a proteger eficientemente parcela considerável da população que ainda não tem condições de autopreservação. A partir de 2002 foram realizados fóruns, grupos de trabalho que serviram para mobilizar diversos setores, tanto local como regionalmente, inserindo profissionais que trabalhavam com crianças menores de seis anos, sendo tal esforço transformado em 2006 na Política Pública de Primeira Infância, um plano que deve ser implementado até 2015. Esta política é fruto de um consenso social que entendeu a necessidade de amparar as crianças menores de seis anos, tendo sido apontado também o grande limite de todos os esforços já realizados, tanto pelo Estado como pela sociedade, que é como efetivar realmente a política, quando serão as mães as responsáveis pela efetivação, isto é, quais as condições garantidas pelo Estado para que a política possa efetivar-se adequadamente. O próximo capítulo trata do fracasso da política pública de aleitamento, mostrando que ela não alcançou o objetivo esperado devido especialmente à falta de recursos educacionais.

O capítulo seguinte trata das políticas públicas para crianças em situação de rua e mostra que, apesar de um rol de normas que buscam viabilizar o acesso ao serviços de saúde, o próprio modo de vida das pessoas, das crianças 
em situação de rua, limita e torna pouco efetiva a garantia prevista na Lei $\mathrm{n}^{\circ}$ 100/1993, que tem como princípio a universalidade. Assim como no Brasil, essa questão ainda está para ser enfrentada de forma adequada, de modo a garantir a implementação do direito para as populações que são vulneráveis, especialmente, as pessoas, adultos ou crianças que estão em situação de rua.

A situação dos deslocados internos, em razão da violência existente na Colômbia, já teve diversas tentativas de garantir benefícios para essa população; há um grande número de normas existentes, que ainda não são suficientes para efetivar a atenção integral para a população que se desloca de forma forçada. Os limites para a implementação das muitas regras existentes são encontrados nos recursos orçamentários insuficientes, bem como na dificuldade de caracterizar este grupo. Os benefícios concedidos como primordiais são a assistência humanitária e o restabelecimento; assim, mesmo com um rol bastante completo de normas que asseguram o acesso ao serviço de saúde, tanto esta como a educação são entendidas como secundárias e, dessa maneira, as políticas de saúde existentes para esta população não encontram significado na realidade.

O último dos capítulos que trata das políticas públicas tem como tema a insuficiência renal crônica terminal e mostra como os gastos com a Terapia de Substituição Renal (IRCT) absorvem um terço dos recursos destinados às Enfermidades de Alto Custo. Entre as causas do aumento da Insuficiência Renal Crônica Terminal (IRCT) estão o aumento da expectativa de vida da população, bem como a não efetividade dos programas de prevenção primária e secundária no controle da hipertensão arterial e da diabetes mellitus. Entre as "políticas" necessárias para modificar esse quadro estão algumas sugestões muito apreciadas no Brasil, que é a valorização da prevenção primária e promoção de estilos de vida saudáveis. Ainda, a revisão dos medicamentos previstos no Plano Obrigatório de Saúde para a inclusão de anti-hipertensivos e hipoglicemiantes, a fim de retardar a insuficiência renal, bem como os imunossupressores para o pós-transplante. E finalmente, a organização de uma campanha nacional de doação de órgãos, bem como a importância de avaliar a Rede Nacional de Transplantes, a fim de garantir a igualdade entre aqueles que necessitam realizar um transplante para ter garantido seu direito à saúde.

E finalmente, no último capítulo, é apresentada uma análise dos atores sociais envolvidos, sendo definido ator social de acordo com o conceito de Touraine: "um ator social pode ser definido, em todas as circunstâncias, por sua posição dentro de um sistema social". ${ }^{5}$

Aqui o autor apresenta todos os atores sociais que estão envolvidos no contexto do sistema de saúde e conclui pela necessidade de participação de todos na busca de soluções para os problemas de saúde. A fim de melhor atender às necessidades de saúde da população e portanto elaborar uma política pública

(5) Políticas públicas en salud, p. 78. 
de saúde, mesmo que setorizada (isto é, para atender um determinado público), mas que possa atingir o objetivo esperado, é necessário integrar os trabalhos administrativo, científico e social, sem colocar o econômico como critério superior que conforma os demais. $\mathrm{O}$ sistema de saúde colombiano apresenta-se como um lócus de pesquisa interessante em razão dos muitos grupos e das questões que atualmente são enfrentadas.

É um sistema de saúde que está em construção, e esse grupo de pesquisa, ao estudar algumas das políticas públicas de saúde na Colômbia, mostra temas de interesse para grande parte dos latino-americanos, ao tratar neste livro, especialmente, do cuidado com a saúde das crianças. As políticas públicas de saúde são entendidas como uma das formas possíveis de efetivar o direito à saúde, mas que necessita da participação dos vários atores sociais envolvidos, pois existe entre o Estado e a sociedade a corresponsabilidade na implementação das propostas. 